Türkiye Jeoloji Bülteni
Geological Bulletin of Turkey
$60(2017) 347-362$
doi:10.25288/tjb.325391

\title{
Khabaz Sahasında (Kuzey Irak) Farklı Rezervuarlardaki Petrollerin Jeoistatistiksel Değerlendirilmesi
}

\author{
Geostatistical Evaluation of Oils in Different Reservoirs of Khabaz
}

Oilfield (Northern Iraq)

\author{
Muhammed İsmail $^{1 *}$, M. Namık Yalçın² ${ }^{\mathbb{D}}$, Torhan M. Al-Mufti ${ }^{3}$ \\ ${ }^{1}$ Khazar University, Department of Petroleum Engineering, 41 Mehseti Street, \\ Baku AZ1096, Azerbaijan \\ ${ }^{2}$ İstanbul Üniversitesi, Jeoloji Mühendisliği Bölümü, 34320 Avcrlar/İstanbul, Türkiye \\ ${ }^{3}$ Kırkuk Technical University, Baghdad Road, Kırkuk 36001, Iraq
}

Geliș/Received : 12.03.2017 • Düzeltilmiș Metin Geliș/Revised Manuscript Received : 29.05.2017 • Kabul/Accepted : 04.06.2017 • Bask1/Printed : 01.08.2017 Arastırma Makalesi/Research Article Türkive Jeol. Bül. / Geol. Bull. Turke

Öz: Kuzey Irak’taki petrol sahalarında petrol üretimi çoğunlukla birden çok rezervuardan yapılmaktadır. Bu rezervuarlar Tersiyer (bir rezervuar) ve Kretase (iki rezervuar) yaşlı birimlerden oluşmaktadır. Bu çalışmada farklı rezervuarlardaki petrollerin tek bir ana kayadan $\mathrm{m} 1$ yoksa farklı ana kayalardan $\mathrm{m}$ türediği ve tek veya çok evreli bir göç sonucunda $\mathrm{m} ı$ bu rezervuarlarda birikmiş oldukları sorularının cevabına ulaşılmaya çalıșılmıștır.

Bu çalışmada incelenen Khabaz petrol sahasında açılmış olan petrol kuyularından hem Tersiyer yaşlı, hem de Kretase yaşlı rezervuarlara ulaşılmış olanlar seçilmiştir. Bu rezervuarlardaki petrollerin özgül ağırlık, API-gravitesi, asfalten miktarı, kükürt miktarı, balmumu miktarı, kül miktarı ve Ni, V miktarları gibi fiziko-kimyasal özellikleri kullanılarak çalışmanın amacına yaklaşım sağlanmıştır. Her bir kuyu ve rezervuar için ayrı ayrı belirlenen bu parametreler, önce bir veri tabanı olarak düzenlenmiştir. Daha sonra korelasyon katsayısı (R), faktör analizi ve klaster (kümelenme) analizi gibi istatistiksel yöntemler yardımıyla bilgisayar destekli değerlendirmeler ve karşılaştırmalar kullanılarak rezervuarlar arasındaki benzerlik, yakınlık ve farklılıklar belirlenmeye çalışılmıştır.

Khabaz petrol sahasında üç ayrı rezervuar bulunmaktadır. Bunlar; Tersiyer yaşlı (Jeribe), Kretase yaşlı (Üst Qamchuqa) ve (Alt Qamchuqa) birimleridir. Khabaz petrol sahasındaki tüm kuyular tek bir yapıdan üretim yapmaktadır. Sadece Khabaz-2b kuyusu bu yapının dışında kalmaktadır. Buradaki petrolün özgül ağırlığı yüksektir ve çok miktarda asfaltik bileşen içermektedir. Değerlendirme sonuçlarına göre üretilen petroller aynı ana kayadan (Chia Gara Formasyonu) türemişlerdir. Bununla birlikte istatistiksel değerlendirmeler sonucunda Khabaz petrol sahasında üretilen petrollerde iki farklı tip petrol (a ve b) belirlenmiştir. Bu bileşimsel farklılı̆̆ın, göç sırasında ve/ veya yerinde başkalaşım sonucunda geliştiği sonucuna varılmıştır.

Anahtar Kelimeler: Faktör analizi, jeoistatistik, petrol jeolojisi, Kerkük petrolleri, petrol jeokimyası.

Abstract: In the oil fields of northern Iraq, oil is generally produced from more than one reservoir. These reservoirs consist of Tertiary (one reservoir interval) and Cretaceous (two reservoir intervals) aged units. In this study we tried to find out whether oil in different reservoirs is formed from a single source rock or from different source rocks and whether they are formed as a result of a single or multi-phase migration.

The Khabaz Oilfield is investigated in this study and wells selected in this field are producing from both Tertiary and Cretaceous reservoirs. Physico-chemical properties of the oils such as specific gravity, API-gravity, amounts of asphaltene, sulfur, wax, ash and $N i, V$ and chemical composition of reservoir water are used in order to achieve the research purpose. Firstly; these parameters, which were separately defined for each well and reservoir, were arranged as a data base. Then by using computer-aided assessments and comparisons the data were compared with each other by the statistical methods such as correlation coefficient (R), factor analysis, and analysis of cluster

*Yazışma / Correspondence: memedchakmakch@yahoo.com

(C) 2017 JMO Her hakkl saklıdır/All rights reserved http://tjb.jmo.org.tr http://dergipark.gov.tr/tjb 
similarity in order to determine similarities, proximities and differences between the reservoirs.

Khabaz oil field has three separate reservoir intervals. These include Tertiary (Jeribe), Cretaceous (Upper Qamchuqa) and Cretaceous (Lower Qamchuqa). According to the results of evaluation, all of the wells produce oil from a single structure in Khabaz oil field. Only Khabaz-2b is located out of this structure. In this field the specific gravity of oil is high and it contains abundant asphaltic components. Oil produced in the Khabaz Field is originated from the same source rock (Chia Gara Formation). However, according to the result of statistical evaluation it is shown that there are two types of oil ( $a$ and b) in the Khabaz oil field. It could be concluded that this compositional difference is caused by degradation of oils during migration and/or in reservoirs,

Key Words: Factor analysis, geostatistics, Kirkuk oils, petroleum geochemistry, petroleum geology.

\section{GíRíş}

Irak petrolce çok zengin ülkelerden biri olup, birden fazla petrol sistemine sahip olması nedeniyle, yakın gelecekte de en önemli petrol üreticilerden biri olmaya devam edecektir. Irak petrol sahalarının çoğunluğu ZagrosMezopotamya kuşağında olup, Kretase-Tersiyer yaşlı bir petrol sistemi ile ilişkilidirler (Şekil 1). Kuzey Irak’taki petrol sisteminde Geç-Jura yaşlı Chia Gara Formasyonunun ana kaya, Kretase yaşlı Üst ve Alt Qamchuqa Formasyonları ile Tersiyer yaşlı Jeribe Formasyonu hazne kaya ve Tersiyer yaşlı Alt Fars Formasyonu örtü kayadır (Buday ve Jassim, 1987).

$\mathrm{Bu}$ sistemin içinde yer alan ve farklı rezervuarlardan üretim yapılan Khabaz petrol sahası bu özellikleri nedeniyle çalışma alanı olarak seçilmiştir. Bu sahada üretim yapılan rezervuarlar Tersiyer (bir rezervuar) ve Kretase (iki rezervuar) yaşlı birimlerden oluşmaktadır. Farklı rezervuarlardan üretilen petrollerin fiziksel ve jeokimyasal özellikleri arasında farklar bulunmaktadir.

$\mathrm{Bu}$ çalışmada, petrollerin bu özelliklerinin jeoistatistiksel olarak incelenmesi yoluyla farklı rezervuarlar, petrollerin tek bir ana kayadan mı yoksa farklı ana kayalardan mı türediği ve tek veya çok evreli bir göç sonucunda $\mathrm{m} ı$ bu rezervuarlarda birikmiş oldukları sorularının cevabına ulaşılmaya çalışılmıştır.

\section{GENEL JEOLOJI}

Kuzey Irak'ta birden fazla rezervuardan petrol üretilmekte olan Khabaz petrol sahası bu bölgenin büyük sahalarından biridir. Khabaz sahası Irak'1n kuzey kesiminde, Kerkük ilinin sınırları içinde şehrin yaklaşık $23 \mathrm{~km}$ batı-kuzeybatısında yer almaktadır. Bu saha, yer altında uzunluğu yaklaşık $12 \mathrm{~km}$, genişliği $4 \mathrm{~km}$ olan ve bir yükselim şeklinde uzanan bir yapı üzerinde yer almaktadır (Abdul-Wahab, 1983).

Khabaz sahası Kerkük sahasının batısında bağıl olarak küçük bir yapı olup, Baba yükselimine paralel olarak uzanır. Kuzeybatısında Bay Hasan sahas1 ve güneydoğusunda Jambur sahası yer almaktadır (Şekil 2 ve 3). Khabaz sahası Kenar Kıvrımları Kuşağı'ndadır ve bu nedenle o kuşağın yapısal özelliklerini taşıması beklenir. Sahanın ekseni kuzeybat1-güneydoğu yönünde uzanır ve kuzeydoğu kanadı güneybatı kanadına göre daha diktir (Jassim vd. 1999; Numan, 1997).

Khabaz petrol sahası önceden Bai Hassan yapısının bir uzantısı olarak düşünülmekte ise de, sismik çalışmaların yorumundan sonra bağımsız bir yap1 olduğu belirlenmiştir (Jassim vd. 1999). $\mathrm{Bu}$ üç petrol sahası Kerkük sahası ana yapısının güneybatısında buna paralel bir şekilde yer almaktadır (Şekil 3). Khabaz petrol sahasında yaklaşık 30 kuyu açılmıştır. Bu kuyuların çoğunun Tersiyer rezervuarlarında sonlanmasına rağmen, bunların yarısından daha fazlası Üst Qamchuqa rezervuarına ulaşmıştır. Sahada birkaç kuyu ise Alt Qamchuqa rezervuarından üretim yapmaktadır. 


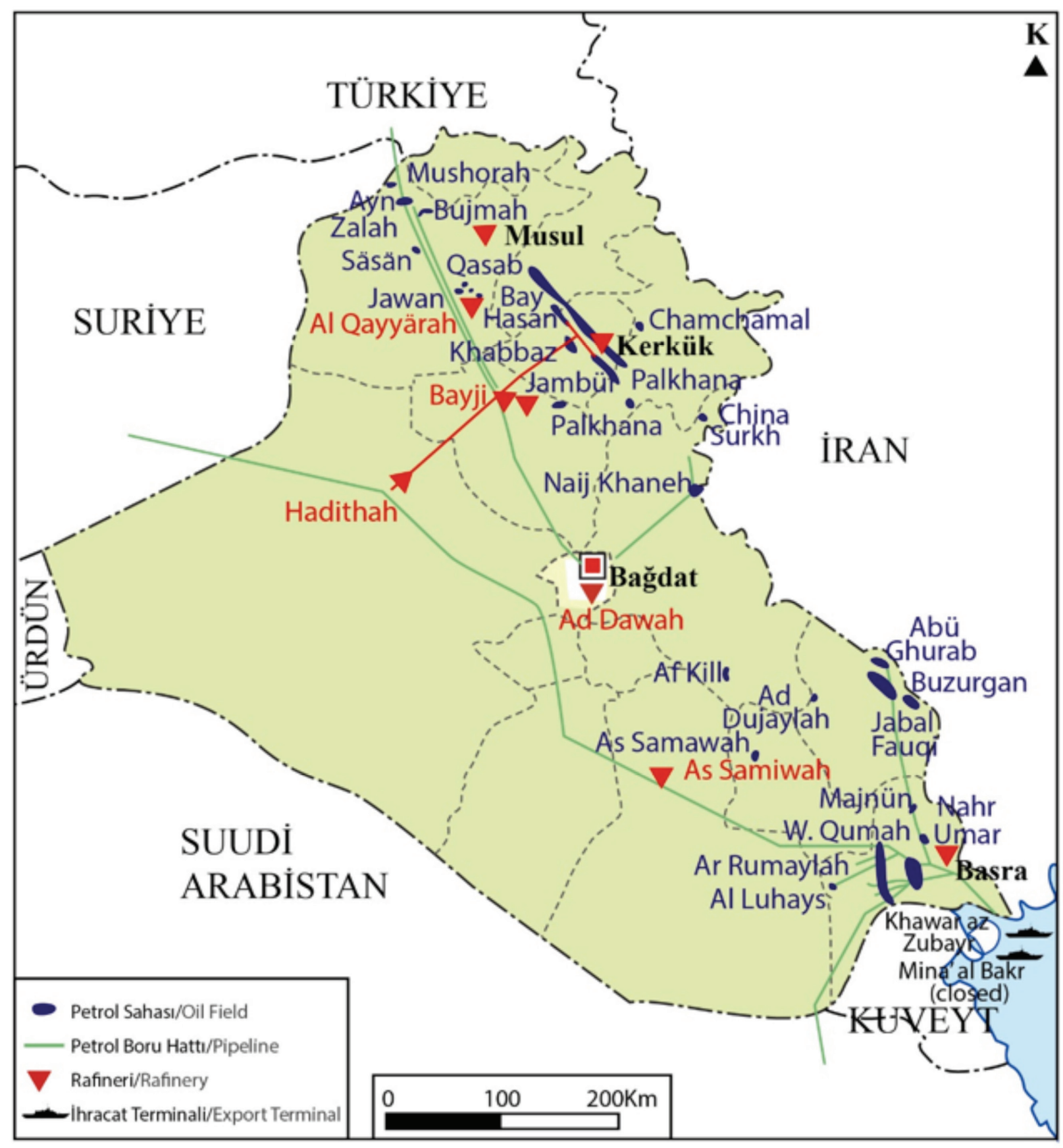

Şekil 1. Irak petrol sahaları haritası (Buday ve Jassim, 1987).

Figure 1. Iraq oil fields map (Buday and Jassim, 1987). 


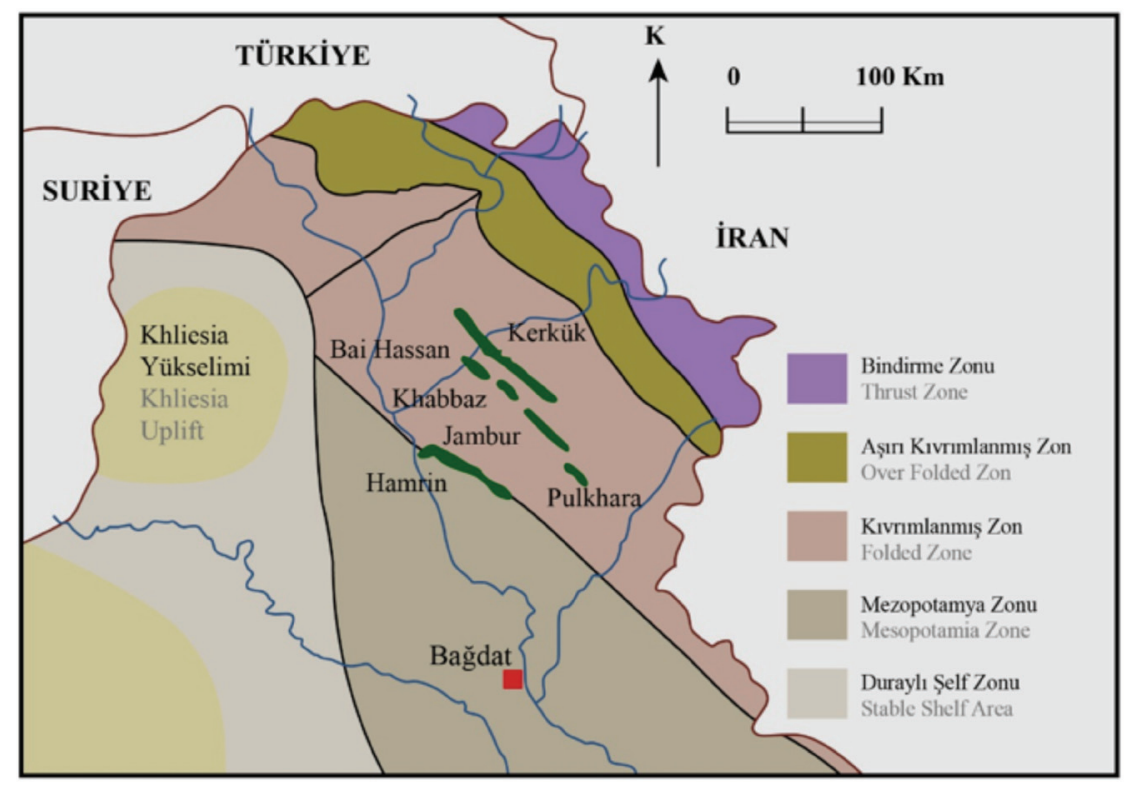

Şekil 2. Khabaz petrol sahasının yerini, bölgedeki yapısal özellikleri ve farklı kuşakları gösterir harita (Buday ve Jassim, 1987).

Figure 2. Map showing the location of the Khabaz oil field and structural characteristics of the region (Buday and Jassim, 1987).

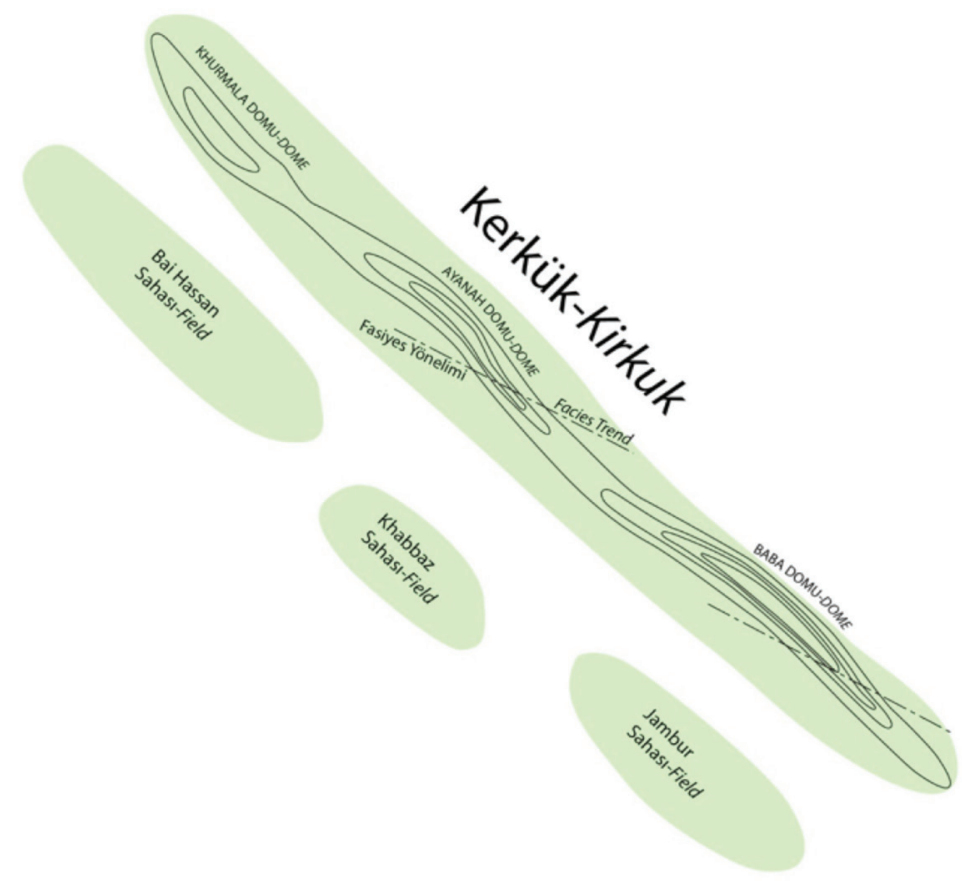

Şekil 3. Khabaz petrol sahasının konumu.

Figure 3. Location of the Khabaz oil field. 


\section{KHABAZ SAHASI PETROLLERININ ÖZELLÍKLERİ}

Irak'ın Kuzey Petrol Şirketi (NOC) tarafından işletmeye alınmış Khabaz petrol sahasında 15 kuyudan derlenen örneklerden Kz-2a, Kz-3, Kz-8, Kz-9, Kz-10, Kz-17, Kz-19, Kz-25 Tersiyer yaşl1 rezervuar kaya nitelikli Jeribe Formasyonundan;
Kz-4, Kz-7, Kz-11, Kz-13 Kretase yaş1ı Üst Qamchuqa biriminden; Kz-1, Kz-2b, Kz-5, Kz14 ise yine Kretase yaşlı Alt Qamchuqa biriminden temin edilmiştir. $\mathrm{Bu}$ örnekler üzerinde yapılmış çalışmalardan elde edilmiş tüm fiziko-kimyasal ve jeokimyasal özellikler bu araştırmada kullanılmıştır. Saptanmış olan özellikler Çizelge 1'de listelenmiştir.

Çizelge 1. Khabaz petrol kuyularında üretilen petrollerin fizikokimyasal ve jeokimyasal özellikleri.

Table 1. Physico-chemical and geochemical properties of oils produced from wells in Khabaz field.

\begin{tabular}{|c|c|c|c|c|c|c|c|c|}
\hline Kuyular & Rezervuar & $\begin{array}{l}\text { Derinlik } \\
(\mathrm{m})\end{array}$ & $\begin{array}{l}\text { API } \\
\text { Gravite }\end{array}$ & $\begin{array}{l}\text { Özgül } \\
\text { Ağ́rlık } \\
\text { gr/cm³ }\end{array}$ & $\begin{array}{l}\text { Kükürt } \\
(\%)\end{array}$ & $\begin{array}{l}\text { Asfalt } \\
(\%)\end{array}$ & $\begin{array}{l}\text { Balmumu } \\
(\%)\end{array}$ & $\begin{array}{l}\text { Kül } \\
(\%)\end{array}$ \\
\hline Khabaz 1 & $\begin{array}{l}\text { Kretase } \\
\text { (Alt Qamchuqa) }\end{array}$ & 3441 & 34.958 & 0.8398 & 1.63 & 1.2 & 4.53 & 0.11 \\
\hline Khabaz 2b & $\begin{array}{l}\text { Kretase } \\
\text { (Alt Qamchuqa) }\end{array}$ & 3528 & 18.20 & 0.9454 & 6.9 & 16.3 & 0.73 & - \\
\hline Khabaz 5 & $\begin{array}{l}\text { Kretase } \\
\text { (Alt Qamchuqa) }\end{array}$ & 3300 & 40.724 & 0.8216 & 2.05 & 0.25 & 1.98 & 0.13 \\
\hline Khabaz 14 & $\begin{array}{l}\text { Kretase } \\
\text { (Alt Qamchuqa) }\end{array}$ & 3295 & 33.958 & 0.8552 & 1.98 & 1.02 & 2.82 & 0.003 \\
\hline Khabaz 4 & $\begin{array}{l}\text { Kretase } \\
\text { (Üst Qamchuqa) }\end{array}$ & 3137 & 22.403 & 0.8716 & 3.85 & 11.2 & 2.8 & 0.022 \\
\hline Khabaz 7 & $\begin{array}{l}\text { Kretase } \\
\text { (Üst Qamchuqa) }\end{array}$ & 3114 & 21.539 & 0.9246 & 3.5 & 3.84 & 2.3 & 0.1 \\
\hline Khabaz 11 & $\begin{array}{l}\text { Kretase } \\
\text { (Üst Qamchuqa) }\end{array}$ & 3070 & 28.567 & 0.884 & 2.8 & 4.35 & 2.85 & 0.069 \\
\hline Khabaz 13 & $\begin{array}{l}\text { Kretase } \\
\text { (Üst Qamchuqa) }\end{array}$ & 3210 & 37.455 & 0.8375 & 1.87 & 1.68 & 1.52 & - \\
\hline Khabaz 2a & Tersiyer & 2668 & 35.5 & 0.8472 & 2.08 & 0.31 & 3.18 & 0.6 \\
\hline Khabaz 3 & Tersiyer & 2749 & 37.576 & 0.8369 & 1.5 & 0.54 & 2.3 & 0.13 \\
\hline Khabaz 8 & Tersiyer & 2300 & 34.677 & 0.8515 & 1.6 & 0.49 & 2.5 & 0.01 \\
\hline Khabaz 9 & Tersiyer & 2310 & 36.652 & 0.8415 & 1.5 & 2.3 & 2.9 & 0.01 \\
\hline Khabaz 10 & Tersiyer & 2376 & 37.374 & 0.8379 & 1.42 & 2.1 & 3.12 & 0.032 \\
\hline Khabaz 17 & Tersiyer & 2360 & 38.225 & 0.8337 & 1.3 & 1.76 & 4.28 & 0.008 \\
\hline Khabaz 19 & Tersiyer & 2319 & 38.001 & 0.8348 & 1.35 & 0.22 & 3.2 & 0.008 \\
\hline Khabaz 25 & Tersiyer & 2343 & 33.264 & 0.8588 & 1.47 & 3.51 & 3.43 & 0.221 \\
\hline
\end{tabular}




\section{Petrollerin Fiziksel Özellikleri}

\section{Özgül ağırlık}

Bir cismin belirli bir hacimdeki ağırlığının, 4 ${ }^{\circ} \mathrm{C}$ sıcaklıkta ve 1 atmosfer basınç altında aynı hacimdeki suyun ağırlığına oranı özgül ağırlık olarak tanımlanır. Khabaz petrol sahasındaki kuyulardan üretilen petrollerin özgül ağırlı̆̆1 genelde 0.82 ile 0.94 arasında değişmektedir. En yüksek özgül ağırlık Khabaz-2b kuyusunda, en düşüğü ise Khabaz-5 kuyusunda saptanmıştır.

\section{API-Gravitesi}

Amerikan Petrol Enstitüsü (API) tarafindan oluşturulan özgül ağırlığa bağlı API gravite değeri, bütün dünyada petrolün sinıflandırılması için genel kabul görmüştür. API Gravite değeri, genelde 10 ile 48 arasında değişmektedir.

Petrollerin API gravitesine göre sınıflandırılması aşağıdaki gibidir:

Hafif $>31$

Orta 20-31

Ağır 10-20

Doğal Bitümler $<10$

Khabaz petrol sahasından çıkan petrollerin API graviteleri genelde 18.2 ile 40 arasindadır. En yüksek API gravitesi Khabaz-5 kuyusunda, en düşük gravite ise Khabaz-2b kuyusunda bulunmuştur.

\section{Petrollerin Jeokimyasal Özellikleri}

\section{Kükürt miktarı}

Kükürt (S) elementi, limon sarısı renkli, katı bir cisimdir ve doğada yaygın bulunan bir elementtir (yer kürenin \% 0.06'sını oluşturur). Inorganik kükürt genelde alçıtaşı ya da kireçtaşı katmanları arasında doğal halde bulunur. Çoğunlukla demir, bakır, kurşun ve çinko sülfürler olarak metallerle birleşmiş olarak görülür (Wikipedia, 2011). Organik kükürt ise daha çok aromatik halkalı hidrokarbon moleküllerinde bulunur (Tissot ve Welte, 1984). Khabaz petrol sahasında en yüksek kükürt değeri \% 6.9 ile Khabaz-2 kuyusunda, en düşük değer ise \% 1.3 ile Khabaz-7 kuyusunda ölçülmüştür.

\section{Asfalt (Asfalten) miktarı}

Ham petrollerin genelde büyük molekül ağırlıklı ve $\mathrm{N}, \mathrm{S}$ ve $\mathrm{O}$ içeren bileşenleri reçineler ve asfaltenler olarak adlandirılır. Asfaltenler ve reçineler karmaşık bir yapıya sahip bileşenlerdir. $\mathrm{Bu}$ yapısal dizilişler çok halkalı-aromatik veya naftanik- aromatik zincirler ile heteroatomlardan $(\mathrm{N}, \mathrm{S}, \mathrm{O})$ oluşturmaktadır. Bunlar petrolün ağır fraksiyonlarını teşkil etmektedirler (Tissot ve Welte, 1984). Khabaz petrol sahasindaki kuyulardan elde edilen asfalten oranları \% 0.22 ile \% 16.3 arasındadır. En yüksek asfalten oranı Khabaz-2b kuyusunda, en düşük oran ise Khabaz-19 kuyusunda elde edilmiştir.

\section{Balmumu miktarı}

Balmumu bir tür kimyasal bileşiktir. $45{ }^{\circ} \mathrm{C}$ üstündeki sıcaklıkta erir ve düşük viskoziteli bir sıv1 oluşturur. Balmumu suda çözülmez, ancak petrolde çözülebilmektedir. Petroldeki balmumu genelde parafinik balmumudur. En çok bulunan doğal balmumu ester olmasına karşın, parafinik balmumu bir hidrokarbondur. $\mathrm{Bu}$ malzemenin önemli bir bölümünü petrol temsil etmektedir. Parafinik balmumu karışımları, n- ve iso alkanlar, naftenler, doymuş, alkil- ve naftenik, aromatik bileşiklerin bir karışımından oluşur (Tissot ve Welte, 1984). Khabaz petrol sahası kuyularından elde edilen en yüksek balmumu değeri \% 4.53 olarak Khabaz-1 kuyusunda, en düşük değer ise \% 0.73 olarak Khabaz-2 kuyusunda belirlenmiştir. 


\section{Nikel ve Vanadyum miktarı}

Nikel (Ni), gümüş - beyaz renkli metalik bir elementtir. Genelde petlandit içinde demir ve kükürt, milerit içinde kükürt ve nikelinin içinde ise arsenik ile birlikte bulunur. Vanadyum (V) yumuşak, gümüşi gri renkli bir diğer metalik elementtir (Wikipedia, 2011). Petrollerin bünyesinde de 1-150 ppm arasında değişen miktarlarda nikel ve vanadyum saptanmıştır (Tissot ve Welte, 1984). Khabaz petrol sahasindan alınan örneklerde en yüksek nikel miktarı 17 ppm ile Khabaz-4 kuyusunda bulunmuştur. En düşük miktar ise Khabaz-1 kuyusundaki 5 ppm dir. Khabaz petrol sahasında alınan örneklerde en yüksek vanadyum miktarı 61 ppm olarak Khabaz-4 kuyusunda, en düşük miktar ise 5 ppm olarak Khabaz-1 kuyusunda ölçülmüştür.

\section{İstatistiksel Değerlendirme}

$\mathrm{Bu}$ çalışmada, Khabaz sahasında üç farklı rezervuardan üretilen petrollerin önceki bölümlerde tartışılmış özellikleri arasındaki ilişkilerin toplu olarak gözetilmesi yoluyla, bu petrollerin kökeni ve göç süreçlerine bir yaklaşım sağlanıp sağlanamayacağı sorusuna istatistiksel yöntemlerle cevap aranmıştır. $\mathrm{Bu}$ amaçla korelasyon katsayısı, faktör analizi ve klaster analizi yaklaşımları denenmiştir.

\section{Korelasyon katsayısı (R)}

$\mathrm{Bu}$ yöntem iki veya daha fazla değişken arasındaki ilişkiyi belirlemek ve bu ilişkinin doğru, ters veya rastgele olup olmadiğını saptamak ve bu değişkenler için bir bütünselliğin sağlanması amacıyla kullanılmaktadır (Al-Rawi, 1980). Korelasyon katsayıs1, mükemmel pozitif korelasyon $(+1)$ ile mükemmel ters korelasyon $(-1)$ ve rastgele ilişki (0) arasında bir değerdir. Genel olarak bu korelasyonu tanımlamak için aşağıda Çizelge 2'de verilen tanımlar kullanılmıştır (AlRawi, 1980).

Çizelge 2. Korelasyonun Korelasyon Katsayısına göre tanımlanması (Al-Rawi, 1980)

Table 2. Definition of correlation according to Correlation Coefficients(Al-Rawi, 1980)

\begin{tabular}{|l|l|}
\hline Korelasyon katsayısı $(\mathrm{R})$ & Korelasyon \\
\hline \pm 1.00 & Mükemmel \\
\hline $\pm 0.75- \pm 0.99$ & Çok Yüksek \\
\hline $\pm 0.50- \pm 0.74$ & Yüksek \\
\hline $\pm 0.25- \pm 0.49$ & Yarı-Yüksek \\
\hline $0.0- \pm 0.24$ & Zayıf \\
\hline
\end{tabular}

Bilgisayar destekli olarak ve saptanan Khabaz sahasında üretilen petrollerin tüm fiziko-kimyasal özellikleri kullanılarak belirlenen korelasyon katsayısı değerleri Çizelge 3'te gösterilmiştir. Elde edilen korelasyon katsayıları (Kz-1, Kz-2a, Kz-3, Kz-5, Kz-8, Kz-10, Kz-14, Kz-17 ve Kz19) kuyuları arasında çok yüksek bir korelasyon olduğunu göstermiştir. Bu kuyuların Kz-1 hariç tümü Tersiyer yaşı Jeribe Formasyonundan üretim yapmaktadır. $\mathrm{Bu}$ da bu rezervuardaki petrollerin çok benzerli olduğu, olasılıkla aynı ana kayadan bir seferde göç etmiş petrollerin söz konusu olduğunu göstermektedir. 
Çizelge 3. Khabaz sahası tüm kuyuları arasındaki korelasyon katsayıları. Kırmızı: Çok Yüksek, Mavi: Yüksek, Sarı: Yarı-Yüksek, Yeşil: Zayıf.

Table 3. Correlation coefficients between all wells of the Khabaz oil field. Red: Very High, Blue: High, Yellow: SemiHigh, Green: Low.

\begin{tabular}{|l|r|r|r|r|r|r|r|r|r|r|r|r|r|r|l|}
\hline Kuyular & Kz-1 & Kz-2 & Kz-3 & Kz-4 & Kz-5 & Kz-7 & Kz-8 & Kz-9 & Kz-10 & Kz-1 & Kz-13 & Kz-14 & Kz-17 & Kz-19 & Kz-25 \\
\hline Kz-1 & 1 & & & & & & & & & & & & & & \\
\hline Kz-2a & 0.97 & 1 & & & & & & & & & & & & & \\
\hline Kz-3 & 0.97 & 0.96 & 1 & & & & & & & & & & & & \\
\hline Kz-4 & 0.35 & 0.28 & 0.45 & 1 & & & & & & & & & & & \\
\hline Kz-5 & 0.85 & 0.92 & 0.92 & 0.40 & 1 & & & & & & & & & & \\
\hline Kz-7 & 0.25 & 0.21 & 0.38 & 0.98 & 0.39 & 1 & & & & & & & & & \\
\hline Kz-8 & 0.97 & 0.96 & 0.99 & 0.45 & 0.93 & 0.38 & 1 & & & & & & & & \\
\hline Kz-9 & 0.70 & 0.57 & 0.73 & 0.83 & 0.51 & 0.73 & 0.72 & 1 & & & & & & & \\
\hline Kz-10 & 0.79 & 0.67 & 0.79 & 0.76 & 0.57 & 0.64 & 0.79 & 0.99 & 1 & & & & & & \\
\hline Kz-11 & 0.30 & 0.20 & 0.38 & 0.98 & 0.28 & 0.95 & 0.38 & 0.85 & 0.77 & 1 & & & & & \\
\hline Kz-13 & 0.48 & 0.45 & 0.62 & 0.94 & 0.62 & 0.94 & 0.62 & 0.81 & 0.75 & 0.89 & 1 & & & & \\
\hline Kz-14 & 0.94 & 0.91 & 0.98 & 0.62 & 0.90 & 0.55 & 0.98 & 0.82 & 0.87 & 0.56 & 0.75 & 1 & & & \\
\hline Kz-17 & 0.90 & 0.78 & 0.86 & 0.56 & 0.62 & 0.43 & 0.86 & 0.91 & 0.96 & 0.57 & 0.59 & 0.88 & 1 & & \\
\hline Kz-19 & 0.99 & 0.96 & 0.97 & 0.31 & 0.84 & 0.21 & 0.97 & 0.69 & 0.78 & 0.26 & 0.46 & 0.92 & 0.89 & 1 & \\
\hline Kz-25 & 0.52 & 0.36 & 0.52 & 0.84 & 0.27 & 0.73 & 0.51 & 0.96 & 0.93 & 0.89 & 0.73 & 0.65 & 0.82 & 0.49 & 1 \\
\hline
\end{tabular}

Buna karşın Kz-1 kuyusu ile Kz-4, Kz-7, $\mathrm{Kz}-11$ ve Kz-13 kuyuları arasındaki korelasyon oldukça düşüktür. Bu dört kuyu Üst Qamchuqa rezervuarında üretim yapılan kuyulardır. $\mathrm{Bu}$ petrollerin Tersiyeryaşlı rezervuardakipetrollerden bir şekilde farklı olduğu anlaşılmaktadır.

Alt Qamchuqa rezervuarından üretim yapan diğer dört kuyu (Kz-1, Kz-2b, Kz-5, Kz-14), $\mathrm{Kz}-2 \mathrm{~b}$ dışında kendi aralarında benzer olup, bu kuyularda üretilen petroller de Tersiyer rezervuarından üretilen petrollere benzemektedir.
$\mathrm{Bu}$ grupların kendi aralarındaki korelasyonu için rezervuar bazında yapılan değerlendirme yukarıdaki sonuçları doğrulamıştır.

Çizelge 4'te Tersiyer yaşlı rezervuardan üretilen petrollerin kendi aralarındaki korelasyonu, Kz-9, Kz-10 ve Kz-25 kuyuları diğerlerinden biraz farklılaşmasına rağmen, tüm kuyuların çok yüksek-yüksek bir korelasyon sunduğunu doğrulamıştır. Kz-9, Kz-10 ve Kz-25 kuyulardaki farklılık bunların yüksek oranda asfalten içermelerinden kaynaklanmaktadır. 
Çizelge 4. Khabaz sahasında Tersiyer yaşlı rezervuardan üretim yapılan kuyular arasındaki korelasyon katsayıları. Kırmızı: Çok Yüksek, Mavi: Yüksek, Sarı: Yarı-Yüksek

Table 4. Correlation coefficients between wells producing from Tertiary aged reservoirs in Khabaz oil field. Red: Very High, Blue: High, Yellow: Semi-High

\begin{tabular}{|l|l|l|l|l|l|l|l|l|}
\hline Kuyular & Kz-2a & Kz-3 & Kz-8 & Kz-9 & Kz-10 & Kz-17 & Kz-19 & Kz-25 \\
\hline Khabaz-2a & 1 & & & & & & & \\
\hline Khabaz-3 & 0.97 & 1 & & & & & & \\
\hline Khabaz-8 & 0.96 & 0.99 & 1 & & & & & \\
\hline Khabaz-9 & 0.57 & 0.73 & 0.72 & 1 & & & & \\
\hline Khabaz-10 & 0.67 & 0.79 & 0.79 & 0.98 & 1 & & & \\
\hline Khabaz-17 & 0.78 & 0.86 & 0.86 & 0.91 & 0.96 & 1 & & \\
\hline Khabaz-19 & 0.96 & 0.97 & 0.97 & 0.69 & 0.78 & 0.89 & 1 & \\
\hline Khabaz-25 & 0.36 & 0.52 & 0.51 & 0.96 & 0.93 & 0.82 & 0.49 & 1 \\
\hline
\end{tabular}

Çizelge 5'te görülen korelasyon ise, (Kz-4, $\mathrm{Kz}-7, \mathrm{Kz}-11, \mathrm{Kz}-13)$ kuyularındaki petrollerin birbirlerine çok benzediğini göstermektedir. $\mathrm{Bu}$ kuyulardaki petrol aynı kaynak kayadan ve olasılıkla aynı evrede göç ederek bu rezervuar kayaya ulaşmış olmalıdır. Bu grubun Tersiyer grubu petrolleriyle olan korelasyonunun düşük oluşu ise farklı bir kökeni veya bir şekilde ayrışmayı işaret etmektedir.

Çizelge 5. Khabaz sahasındaki Kretase yaşlı Üst Qamchuqa rezervuarından üretim yapan kuyular arasındaki korelasyon katsayıları. Kırmızı: Çok Yüksek.

Table 5. Correlation coefficients between wells producing from the Upper Qamchuqa reservoir of Cretaceous age in the Khabaz oil field. Red: Very High.

\begin{tabular}{|l|l|l|l|l|}
\hline Kuyular & Kz-4 & Kz-7 & Kz-11 & Kz-13 \\
\hline Khabaz-4 & 1 & & & \\
\hline Khabaz-7 & 0.98 & 1 & & \\
\hline Khabaz-11 & 0.98 & 0.95 & 1 & \\
\hline Khabaz-13 & 0.94 & 0.94 & 0.89 & 1 \\
\hline
\end{tabular}

Çizelge 6'daki Kretase yaşlı (Alt Qamchuqa) rezervuarındaki petrollerin korelasyon sonucuna göre, (Kz-1, Kz-5, Kz-14) kuyularındaki petroller birbirlerine çok benzemekte ve aynı zamanda Tersiyer rezervuarındaki petroller ile de çok yakın benzerlikler sunmaktadir. $\mathrm{Bu}$ nedenle bu petrollerin de aynı kökenden gelme olasılıkları oldukça yüksektir. Khabaz-2b kuyusundaki petrol ise yüksek orandaki asfalten içeriği nedeniyle ayrı düşmüştür. Bu korelasyon sonucunda da Khabaz petrol sahasının Kretase yaşlı Alt Qamchuqa rezervuardaki tüm kuyuların, Khabaz-2b hariç, aynı petrol tipini içerdikleri anlaşılmıştır. 
Çizelge 6. Khabaz sahasındaki Alt Qamchuqa rezervuarında üretim yapan kuyular arasındaki korelasyon katsayıları. Kırmızı: Çok Yüksek, Mavi: Yüksek, Sarı: Yar1-Yüksek

Table 6. Correlation coefficients between the wells producing in the Lower Qamchuqa reservoir in the Khabaz oil field. Red: Very High, Blue: High, Yellow: Semi-High

\begin{tabular}{|l|l|l|l|l|}
\hline Kuyular & Kz-1 & Kz-2b & Kz-5 & Kz-14 \\
\hline Khabaz-1 & 1 & & & \\
\hline Khabaz-2b & 0.59 & 1 & & \\
\hline Khabaz-5 & 0.85 & 0.58 & 1 & \\
\hline Khabaz-14 & 0.94 & 0.41 & 0.90 & 1 \\
\hline
\end{tabular}

\section{Klaster (Cluster) analizi}

Klaster analizi yönteminin temeli, bir veri serisi içindeki benzer değerlere sahip olanları gruplandırarak birbirinden farkl11ıklar sunan verilerin ayırt edilmesi olarak ifade edilebilir. $\mathrm{Bu}$ yöntemin özelliği çok ayrıntılı ve net bir sinıflandırmaya izin vermesidir. Verilerin aynı özellikleri taşıyanları ve benzer olanları, bunların kökenini anlamak için de kullanılmaktadır (AlRawi, 1980)

Khabaz petrol kuyularındaki petrollerin özellikleri kullanılarak bilgisayar destekli Klaster analizi yardımıyla bu petrollerin gruplandırılmasına ve varsa farklı olanların belirlenmesine çalışılmıştır. Bu amaçla önce farklı rezervuarlardan üretim yapılan kuyuları temsilen 10 kuyu için bir ön değerlendirme yapılmıştır.
Değerlendirilen kuyulardan Kz-4 ve Kz-13 Üst Qamchuqa'y1, Kz-1 ve Kz-14 Alt Qamchuqa'y1, Kz-2a, Kz-8, Kz-10, Kz-17, Kz-19 ve Kz-25 Tersiyer'i temsil etmektedir. Bu ön değerlendirme, Kz-2a, Kz-8, Kz-19 ve Kz-14 kuyuların yakın ilişki olduklarını, Kz-4 kuyusunun ise en uzak ilişkili olduğunu göstermiştir (Şekil 4).

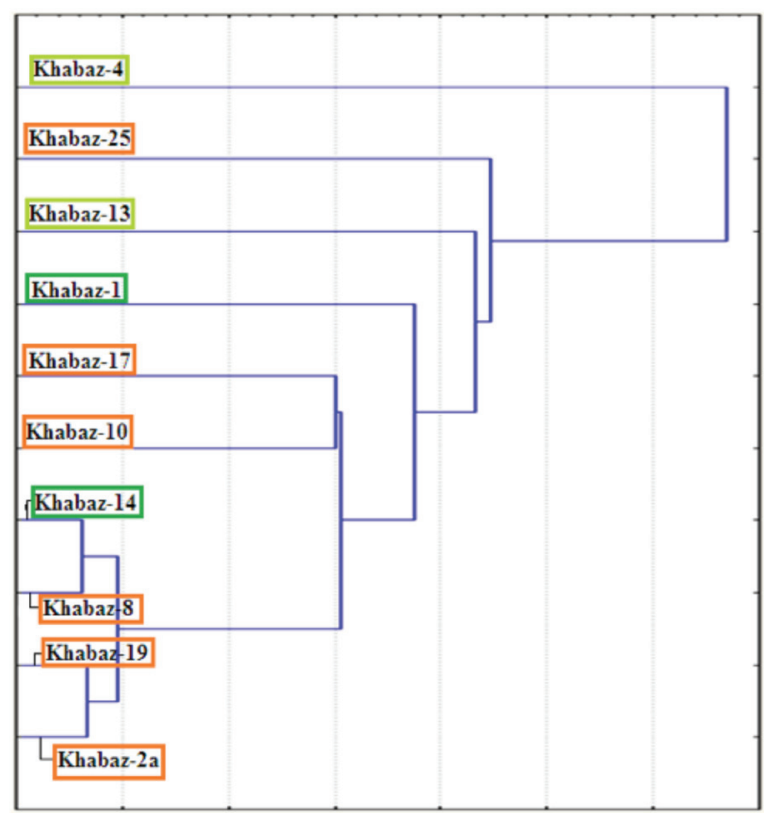

Şekil 4. Khabaz sahasında farklı rezervuarlardan üretim yapan 10 kuyunun klaster diyagramı.

Figure 4. Cluster diagram of 10 wells producing from different reservoirs in Khabaz field.

Klaster analizi daha sonra farklı rezervuardan üretilen petroller bazında ayrı ayrı yapılmıştır. Khabaz sahasında Tersiyer yaşlı rezervuardan üretim yapılan kuyuların iki temel grup oluşturdukları görülmektedir (Şekil 5). 


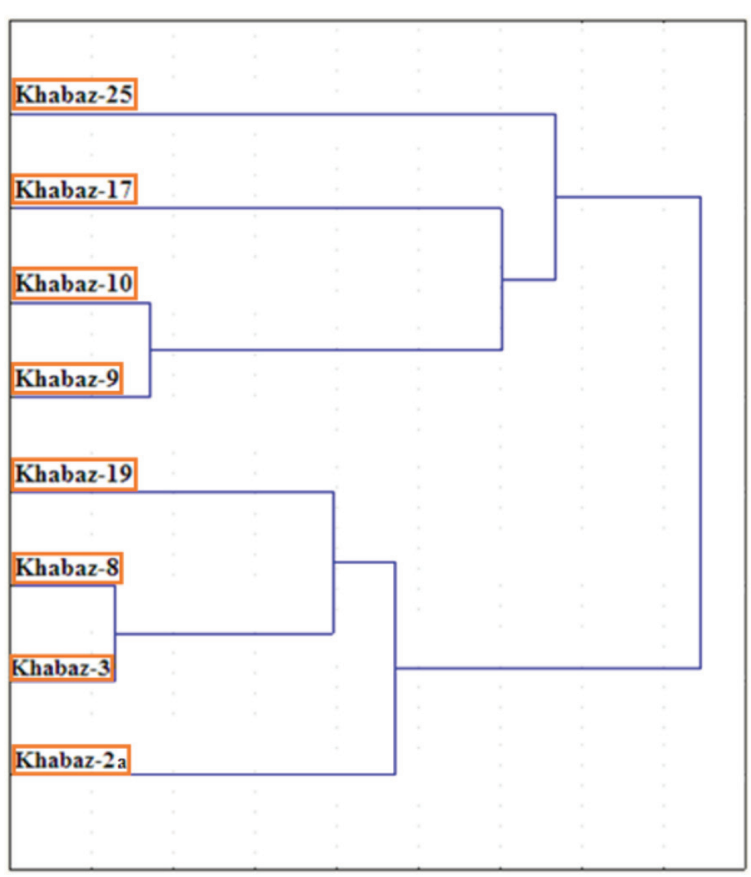

Şekil 5. Khabaz sahası Tersiyer yaşlı rezervuarlardaki petrollerin klaster diyagram1.

Figure 5. Cluster diagram of oil wells in the Khabaz field producing from Tertiary age reservoir.

Elde edilen sonuçlara göre $\mathrm{Kz}-25, \mathrm{Kz}-17$, Kz-10 ve Kz-9 birinci gruba, Kz-19, Kz-8, Kz-3 ve Kz-2a ise ikinci gruba aittir. Gruplaşmanın nedeni birinci gruptaki kuyulardaki petrollerde $\%$ 1.76'dan yüksek oranda asfalten, ikinci gruptaki kuyulardaki petrollerde ise \% 0.54 'ten düşük asfalten bulunmasıdır. $\mathrm{Bu}$ iki farklı gruplaşmaya rağmen Şekil 5'teki diyagram ortak bir kökene işaret etmektedir. Ayrıca bu sonuç, korelasyon katsayıları gözetilerek yapılmış olan değerlendirmeyle de uyumludur.

Khabaz sahasının Kretase yaşlı Üst ve Alt Qamchuqa rezervuarındaki kuyulardan elde edilen sonuçlara göre, iki ayrı tip petrol bulunmaktadır (Şekil 6). Bunlardan Üst Qamchuqa rezervuarından üretim yapan Kz-4, Kz-7 ve Kz-11 kuyularında çok benzer petroller bulunmaktadır. Yine Üst Qamchuqa rezervuarından üretim yapan Kz-13 kuyusu da bir ölçüde bunlara benzer özelliklere sahiptir. Alt Qamchuqa rezervuarından üretim yapan Kz-1, Kz-5 ve Kz-14 kuyuları ise diğer grubu oluşturmaktadır. İki ayrı petrol grubunun farklı iki rezervuarı temsil ediyor oluşu dikkat çekicidir. Kz-2b kuyusu ise bu iki gruptan ayrı özelliklere sahiptir. Bunun olası nedeni Kz-2b deki petrolün çok yüksek oranda asfalten içermesidir.

Klaster analizi sonuçlarına göre de Tersiyer yaşlı rezervuardaki petrollerin oluşturduğu bir grup ile Üst Qamchuqa rezervuarındaki bir diğer grup birbirlerinden ayrılmaktadır. Alt Qamchuqa ise daha çok Tersiyer yaşlı kuyulardaki petrole yakındir.

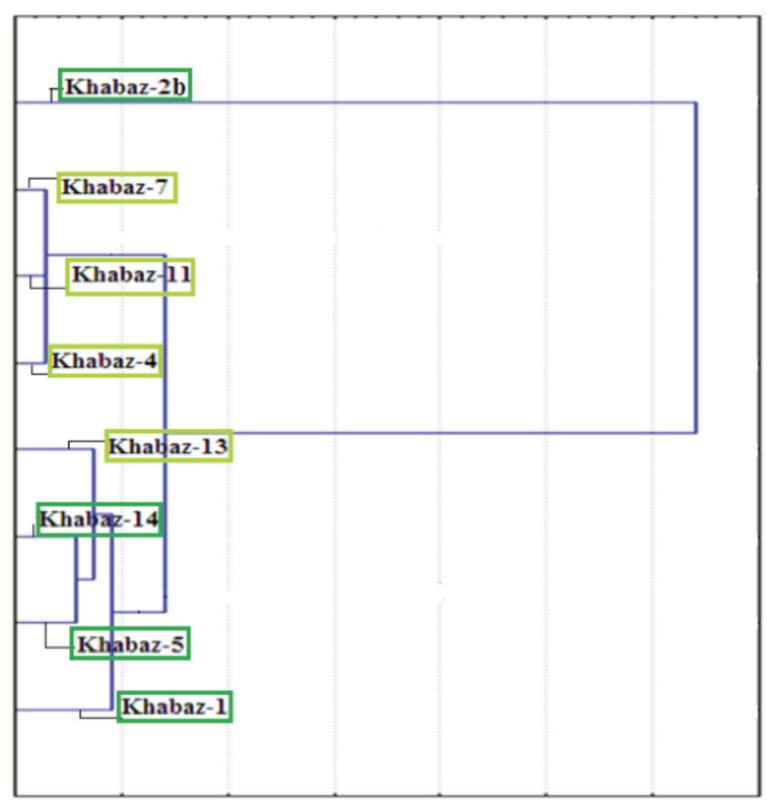

Şekil 6. Khabaz sahası Kretase yaşlı rezervuarlardaki petrollerin klaster diyagram1.

Figure 6. Cluster diagram of oil wells in the Cretaceous reservoirs in Khabaz oil field.

\section{Faktör analizi}

Faktör analizi, çok değişkenli bir veri setinde farklılık-değişiklik matrisi içindeki yapıları ve ilişkileri yorumlamak için kullanılmaktadır. Kullanılan teknik, korelasyon veya değişiklik 
matrisinden öz değer ve öz vektörlerin çıkarılmasına dayanmaktadır (Kline, 1994; Wikipedia, 2011).

Çalışmada, bilgisayar destekli faktör analizi yapılarak Khabaz sahası kuyularındaki petrollerin fiziko-kimyasal özellikleri arasındaki ilişkinin belirlenmesi amaçlanmıştır. Temsilci 10 kuyu seçilerek yapılan ön değerlendirmeler özgül ağırlık, kükürt ve balmumu değerlerindeki değişimlerin benzerlikler sunduğunu göstermiştir (Çizelge 7).

Çizelge 7. Khabaz sahasının farklı rezervuarlardan üretim yapan 10 kuyunun özellikleri arasındaki faktör analizi.

Table 7. Factor analysis of the characteristics between 10 wells that producing from different reservoirs in Khabaz oil field.

\begin{tabular}{|l|l|l|}
\hline Değişken & Faktör 1 & Faktör 2 \\
\hline Özgül ağırlık & 0.845436 & 0.326528 \\
\hline Kükürt & 0.730547 & 0.271109 \\
\hline Asfalten & 0.444043 & 0.683342 \\
\hline Balmumu & 0.666055 & 0.028111 \\
\hline Kül & 0.288084 & 0.847516 \\
\hline $\begin{array}{l}\text { Değişkenlik } \\
\text { (Expl. Var.) }\end{array}$ & 1.972257 & 1.366151 \\
\hline $\begin{array}{l}\text { Toplam Oran } \\
\text { (Prp. Totl) }\end{array}$ & 0.394451 & 0.273230 \\
\hline
\end{tabular}

Daha sonraki aşamada ise Tersiyer ve Kretase yaşlı rezervuarlardaki petroller ayrı ayrı değerlendirilmiştir. Yapılan bu değerlendirme Tersiyer yaşlı rezervuarlardaki kuyularda kükürt, asfalten ve balmumu arasında çok yüksek bir ilişkinin olduğunu göstermiştir (Çizelge 8 ).
Çizelge 8. Tersiyer yaşlı rezervuardaki petrollerin özellikleri arasındaki faktör analizi.

Table 8. Factor analysis between the characteristics of oil in Tertiary age reservoir.

\begin{tabular}{|l|l|l|}
\hline Değişken & Faktör 1 & Faktör 2 \\
\hline Özgül ağırlık & 0.557260 & 0.760109 \\
\hline Kükürt & 0.784538 & 0.548480 \\
\hline Asfalten & 0.802926 & 0.305681 \\
\hline Balmumu & 0.725791 & 0.188060 \\
\hline Kül & 0.478565 & 0.784022 \\
\hline Değişkenlik & 2.326526 & 1.622093 \\
\hline Toplam Oran & 0.465305 & 0.324419 \\
\hline
\end{tabular}

Kretase (Üst ve Alt Qamchuqa) yaşlı rezervuarlardaki kuyularda ise özgül ağırlık, kükürt ve asfalten arasında çok yüksek bir ilişki bulunmaktadır (Çizelge 9).

Çizelge 9. Kretase yaşlı rezervuarlardaki petrollerin özellikleri arasındaki faktör analizi.

Table 9. Factor analysis between characteristics of oils in Cretaceous reservoirs.

\begin{tabular}{|l|l|l|}
\hline Değişken & Faktör 1 & Faktör 2 \\
\hline Özgül ağırlık & 0.920884 & 0.021512 \\
\hline Kükürt & 0.973968 & 0.127708 \\
\hline Asfalten & 0.966552 & 0.096445 \\
\hline Balmumu & 0.313150 & 0.485971 \\
\hline Kül & 0.234666 & 0.865727 \\
\hline Değişkenlik & 2.883997 & 1.011724 \\
\hline Toplam Oran & 0.576799 & 0.202345 \\
\hline
\end{tabular}

$\mathrm{Bu}$ sonuçlar, Tersiyer ve Kretase rezervuarlarındaki petrollerin kısmen ayrışmakla beraber benzerlikler gösterdikleri şeklinde yorumlanmıştır. 


\section{TARTIŞMA VE SONUÇLAR}

Bu çalışmada elde edilen verilerin 1şığında Khabaz petrol sahasında iki ayrı tip petrolün bulunduğu sonucuna varılmıştır (Şekil 7). Bunlardan; Tersiyer yaşlı rezervuar kayalarından (Jeribe Formasyonu) üretim yapılan kuyulardaki petrol (Kz-2a, Kz-3, Kz-8, Kz-19) "a petrolü” olarak adlandırılmıştır. Aynı rezervuardan üretim yapılan (Kz-9, Kz-10, $\mathrm{Kz}-17, \mathrm{Kz}-25)$ kuyulardaki petrol de bu gruba ait olmakla birlikte bazı küçük bileşimsel farklılıklar nedeniyle diğer kuyulardan ayrışmaktadır. Bunun nedeni birinci grup kuyulardaki petrollerde \% 0.54 'ten düşük oranda asfaltenler bulunmas1, ikinci gruptaki kuyulara ait petrollerde ise asfalten miktarının \% 1.76' dan yüksek olmasıdır.

Khabaz petrol sahasindaki Kz-4, Kz-7, Kz-11, Kz-13 kuyularında Kretase yaşlı Üst Qamchuqa rezervuarından üretilen petrol ise " $b$ petrolü” olarak adlandırılmıştır. Bunun ilk gruptan ayrılmasının temel nedeni, Kz-13 kuyusu dışında düşük API gravitesine sahip olmaları ve yüksek oranda asfalten içermeleridir.

Khabaz petrol sahasında Kretase yaşlı Alt Qamchuqa rezervuarından üretim yapan $\mathrm{Kz}-1$, $\mathrm{Kz}-2 \mathrm{~b}, \mathrm{Kz}-5, \mathrm{Kz}-14$ ise ağırlıklı olarak "a petrolü" içermektedir. Bu kuyulardan Kz-2b' deki petrol çok yüksek oranda asfalten içermesi ( $\%$ 16.3) nedeniyle tüm diğer petrollerden farklılaşmaktadır.

Özellikleri farklı iki grup petrolün varlığ1, bu petrollerin iki farklı ana kayadan türemiş olmaları veya tek bir ana kayadan farklı olgunluk aşamalarında türeyerek ve bu ana kayadan farklı zamanlarda atılarak göç etmeleri ile açıklanabilir. Bunun yanı sıra iki farklı petrolün varlığı, bunların tek bir ana kayadan türemeleri, tek bir evrede göç ederek rezervuarlarda birikmeleri, ancak burada daha sonra başkalaşmış olmaları (transformasyona uğraması) ile de açıklanabilir.

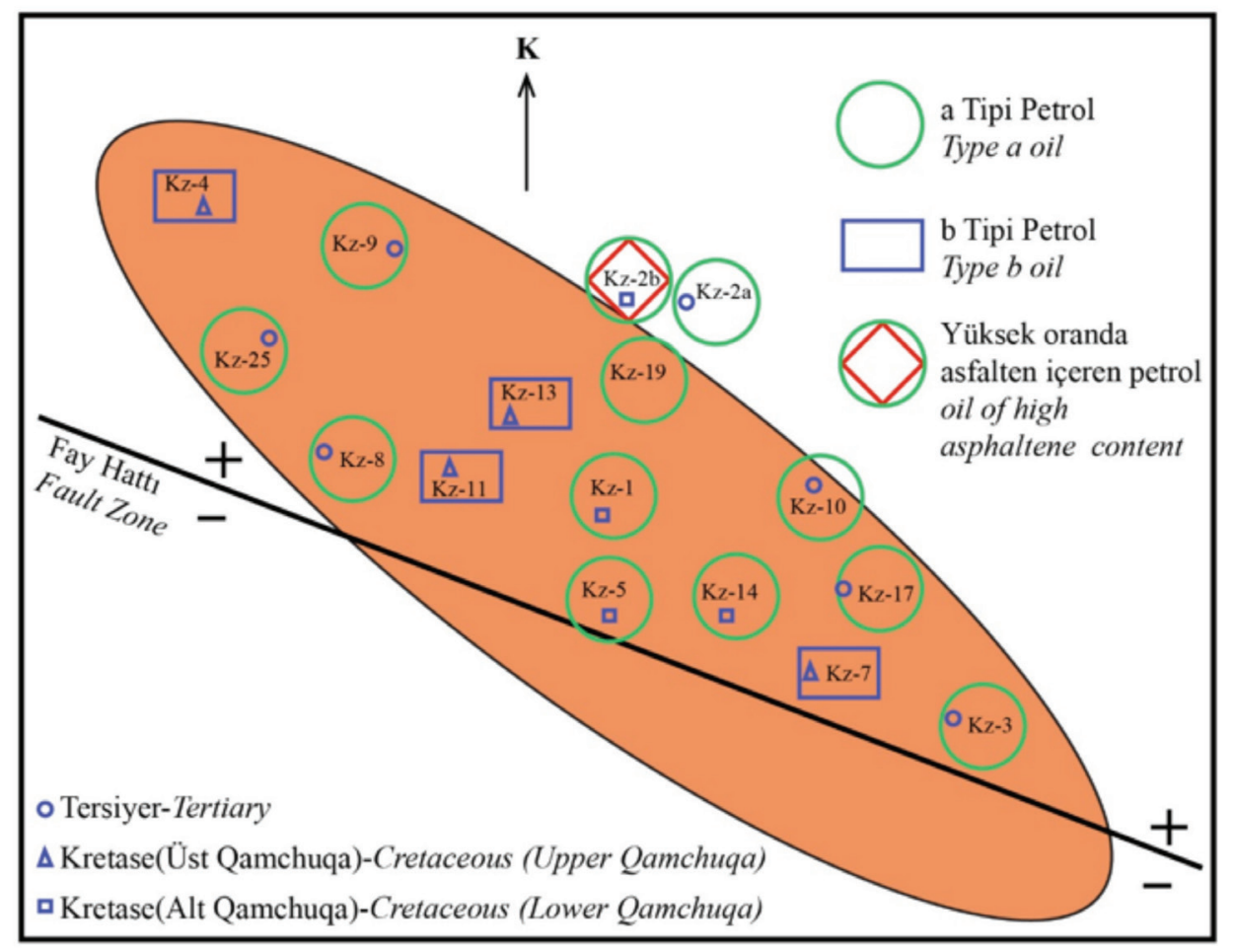

Şekil 7. Khabaz petrol sahasındaki petrol tiplerini gösterir harita.

Figure 7. Map showing oil types in Khabaz oil field. 
Kuzey Irak ve Khabaz petrol sahasinın petrol jeolojisi ve petrollerin saptanan özelliklerinin değerlendirilmesi yoluyla bu olasılıklar aşağıda tartış1lmıştır:

Daha öncekiçalışmalarda(Habba veAbdullah, 1989) saptanmış olduğundan, Kuzey Irak’ta ve Khabaz petrol sahasinda üretilen petrollerin tek bir ana kayadan (Chia Gara Formasyonu) türemiş olmaları çok yüksek bir olasılıktır. Ayrıca petrollerin özellikleri arasında farklılıklar bulunsa da, bunların sınırlı oluşu, üretilen petrollerin aynı kökenden geldiğine işaret etmektedir. Bunlar, yukarıda sözü edilen ilk olasılığın (farklı ana kayalar) mümkün olmadığını göstermektedir.

İkinci olasılık, Khabaz petrol sahasındaki özellikleri farkı petrollerin aynı ana kayadan (Chia Gara Formasyonu), ancak iki farklı olgunluk aşamasında oluşup, atılarak göç etmiş olmalarıdır. Bunun için ilk aşamada, Khabaz sahası yakınlarındaki bir depresyonda (Kitchen Area) Chia Gara Formasyonunda erken olgun aşamada oluşmuş düşük API graviteli ve yüksek asfalten içerikli petrollerin göç ederek Üst Qamchuqa Formasyonu'nda birikmiş olmaları, bunu takip eden dönemde ise artan gömülmeye bağlı olarak daha olgun bir evrede yüksek API graviteli ve düşük asfalten içerikli petrollerin Jeribe ve Alt Qamchuqa rezervuarına göç ederek birikmeleri gerekecektir. Ancak, Kuzey Irak Petrol Sisteminde Chia Gara Formasyonun'daki petrol oluşumunun mekan ve zamandaki dağılımı (Pitman vd. 2004) bu senaryoyu desteklememektedir. Bunun yanı sıra farklı dönemlerde göç eden petrollerin farklı rezervuarları tercih etmiş olmalarının jeolojik bir gerekçesi bulunmamaktadır. $\mathrm{Bu}$ nedenlerle yukarıda sözü edilen ikinci olasılığın da (tek bir ana kaya, farklı olgunluk aşamalarında göç) mümkün olmadığı sonucuna varılmıştır.

Sonuç olarak, Kuzey Irak'ta ve Khabaz petrol sahasındaki petrollerin bazı kuyularda farkl1 özellikler göstermesinin, aynı ana kayadan ve tek bir evrede göç etmiş petrollerin daha sonra rezervuar koşullarında başkalaşmış olmaları ile ilgili olabileceği daha yüksek bir olasılık olarak değerlendirilmiştir. Bunun nedeni, farklılıkların öncelikle API gravitesi ve asfalten oranına dayanması (Çizelge 10) ve bu özelliklerin de yerinde başkalaşım süreçlerinden etkilenmeleridir.

En önde gelen yerinde başkalaşım süreci ise biyodegradasyon olarak değerlendirilmiştir. Farklılıklar sunan petrollerin moleküler organik jeokimyasal özellikleri bilinmediğinden bu farklılaşmanın biyodegradasyondan kaynaklanıp kaynaklanmadığı belirlenememiştir. Bununla beraber, Kz-2b kuyusundaki aşırı yüksek asfalten oranı ve buna bağl1 düşük API gravitesi bunun olas olduğuna işaret etmektedir. Başkalaşmış petrollerin ağırlıklı olarak Üst Qamchuqa rezervuarında bulunmaları, başkalaşıma neden olan süreçlerin bu rezervuar kayanın diğer özellikleri ile de kontrol edildiğini düşündürmektedir.

Khabaz sahasında farklı rezervuarlardaki petrollerde saptanmış olan bileşimsel farklılıkların, göç sırasında ve/veya yerinde başkalaşım sonucunda geliştikleri sonucuna varılmıştır. 
Çizelge 10. Khabaz sahasındaki petrollerin özelliklerindeki temel farklılıklar.

Table 10. Basic differences in the characteristics of oils in the Khabaz field.

\begin{tabular}{|l|l|l|l|l|}
\hline Kuyular & Rezervuar & Derinlik $(\mathrm{m})$ & API & Asfalten \% \\
\hline Khabaz-8 & Tersiyer & 2300 & 34.7 & 0.49 \\
\hline Kahabz-9 & Tersiyer & 2310 & 36.7 & 2.3 \\
\hline Kahabz-19 & Tersiyer & 2319 & 38.0 & 0.22 \\
\hline Khabaz-25 & Tersiyer & 2343 & 33.2 & 3.51 \\
\hline Khabaz-17 & Tersiyer & 2360 & 38.2 & 1.76 \\
\hline Khabaz-10 & Tersiyer & 2376 & 37.4 & 2.1 \\
\hline Khabaz-2a & Tersiyer & 2668 & 35.5 & 0.31 \\
\hline Khabaz-3 & Tersiyer & 2749 & 37.6 & 0.54 \\
\hline Khabaz-11 & Kretase (Üst Qamchuqa) & 3070 & 28.7 & 4.35 \\
\hline Khabaz-7 & Kretase (Üst Qamchuqa) & 3114 & 21.5 & 3.84 \\
\hline Khabaz-4 & Kretase (Üst Qamchuqa) & 3137 & 22.4 & 11.2 \\
\hline Khabaz-13 & Kretase (Üst Qamchuqa) & 3210 & 37.4 & 1.68 \\
\hline Khabaz-14 & Kretase (Alt Qamchuqa) & 3295 & 34.0 & 1.02 \\
\hline Khabaz-5 & Kretase (Alt Qamchuqa) & 3300 & 40.7 & 0.25 \\
\hline Khabaz-1 & Kretase (Alt Qamchuqa) & 3441 & 35.0 & 1.2 \\
\hline Khabaz-2b & Kretase (Alt Qamchuqa) & 3528 & 18.2 & 16.3 \\
\hline
\end{tabular}

\section{KATKI BELIRTME}

$\mathrm{Bu}$ makale birinci yazar tarafindan İstanbul Üniversitesi Fen Bilimleri Enstitüsü Jeoloji Mühendisliği Anabilim Dalı'nda Yüksek Lisans Tezi olarak hazırlanmış olan çalışmadan yararlanılarak hazırlanmıştır. Khabaz Petrol Sahası ve bu sahada üretilen petrollere ait verileri sağlayan Kuzey Petrol Şirketi'ne teşekkür borçluyuz. Makaleyi özenle değerlendirerek, yapıcı eleştirileriyle yol gösterici olan Doç. Dr. Nazan Yalçın Erik (Cumhuriyet Üniversitesi) ve Dr. Zühtü Batı'ya (Türkiye Petrolleri A. O.) da katkıları için özellikle teşekkür ederiz.

\section{EXTENDED SUMMARY}

Iraq is one of the so-called oil-rich countries and will also remain in the future as one of the major oil producers, as it consists of various petroleum systems. Most of the Iraqu oil fields are located in northern Iraq within the Zagros-Mesopotamian Belt and are related with a Cretaceous-Tertiary petroleum system (Figure 1). The Khabaz Oilfield which is investigated in this study belongs to the province of the Kirkuk oils. It is located to the southwest of the Kirkuk field and runs parallel to this field in a northwest-southeast direction (Figures 2 and 3). In this field oil is produced from approximately 30 wells, most of which are penetrated only the Tertiary reservoirs. But, some of these wells are also producing from Cretaceous Upper and Lower Qamchuqa units.

In this study we tried to find out whether oil in these different reservoirs is formed from a single source rock or from different source rocks and whether they are formed as a result of a single or multi-phase migration. For this purpose, physico-chemical properties of the oils such as specific gravity, API-gravity, amounts of asphaltene, sulphur, wax, ash and $N i, V$ and chemical composition of reservoir water are used. These parameters, which were separately defined for each well and reservoir, are arranged as a data base. By using computer-aided assessments 
and comparisons the data are compared with each other by statistical methods such as correlation coefficient (R), factor analysis, and analysis of cluster similarity in order to determine similarities, proximities and differences between the reservoirs.

The conducted statistical evaluation has shown that remarkable compositional differences do exist. Whereas oils in Tertiary and Upper Qamchuqa reservoirs (Type a oil) are similar, the oil in Lower Qamchuqa reservoir (Type b oil) is different due to its low API-gravity and high asphalten content. The existence of these two different oils can be explained either by two different source rocks or by only one source rock, which feeded these reservoirs as a result of a multiphase generation and migration. Furthermore, an in-situ transformation of oil from a single source rock and a single-phase migration can be considered as another plausible explanation.

Validity of these possible explanations is discussed in the light of previous studies on the petroleum geology of Northern Iraq and of the Khabaz Field (Habba and Abdullah, 1989; Pitman et al., 2004), and of the results of this geostatistical study. According to the results of this discussion, the following items could be concluded:

-Although some compositional differences are observed, both oils are generated most probably from a single source rock, namely the late Jurassic Chia Gara Formation, because the differences are not major. Therefore, the option of two source rocks can be excluded.

-A multi-phase generation and subsequent migration from a single source rock is considered also as not possible, since the temporal and spatial distribution of oil generation in Chia Gara Formation and the geologic history of Northern Iraq does not support this scenario (Pitman et al., 2004).
- It could be concluded that the compositional differences of oils observed in different reservoirs are caused by in-situ degradation of oil in reservoirs, because the differences are mainly related with API-gravity and asphalten content, the most sensitive parameters to degradation.

\section{DEĞINIILEN BELGELER}

Abdul-Wahab, L.M., 1983. Mineralogy of amphiboles and pyroxenes from recent sediments of the Tigris, Diyala and Adhaim Rivers, Iraq, Yüksek Lisans Tezi, University of Keele, UK, p. 55-57

Al-Rawi., 1980. Provenance of Miocene Sandstones in Northern Iraq: Constraints from Framework Petrography, Bulk-Rock Geochemistry and Mineral Chemistry, Russian Geology and Geophysics, 50(2009), p. 517-534.

Buday, T. ve Jassim, S. Z., 1987. The Regional Geology of Iraq, Volume II; Tectonism, Magmatism and Metamorphism. Dar AL-Kutib publishing house, University of Mosul. Iraq. 352 p

Habba, Y ve Abdullah, M. B., 1989. Geochemical Study of the Hydrocarbon Source Rocks in Northeast Iraq. Oil \& Arab Co-operation, 15, p. 12-51.

Jassim, S.Z., Raiswell, R., ve Bottrell, S.H., 1999. Genesis of Middle Miocene strata bound Sulphur deposits of northern Iraq. Journal of the Geological Society, London 156, P. 25-39.

Kline, P., 1994. An Easy Guide to Factor Analysis. London, New York: Routledge, 194 pp.

Numan, N.M.S., 1997. A plate tectonic scenario for the Phanerozoic succession in Iraq. Iraqi Geological Journal 30, 85-110.

Pitman, J. K., Steinshouer, D. ve Lewa, M. D., 2004. Petroleum generation and migration in the Mesopotamian basin and Zagros fold belt of Iraq, Geology of Iraq, first ed., Brno, Czech Republic, p. 243-249.

Tissot, B.P. ve Welte, D.H., 1984. Petroleum formation and occurrence. Springer-Verlag, New York, 699 pp.

Wikipedia, 2011: http://tr.wikipedia.org, accessed on 20 February 2011. 